\title{
Effects of maternal obesity on placental function and fetal development
}

\author{
Kristy R Howell and Theresa L Powell \\ Departments of Psychiatry, Obstetrics/Gynecology and Pediatrics, University of Colorado, \\ Anschutz Medical Campus, Aurora, Colorado, USA \\ Correspondence should be addressed to T L Powell; Email: theresa.powell@ucdenver.edu
}

\begin{abstract}
Obesity has reached epidemic proportions, and pregnancies in obese mothers have increased risk for complications including gestational diabetes, hypertensive disorders, pre-term birth and caesarian section. Children born to obese mothers are at increased risk of obesity and metabolic disease and are susceptible to develop neuropsychiatric and cognitive disorders. Changes in placental function not only play a critical role in the development of pregnancy complications but may also be involved in linking maternal obesity to long-term health risks in the infant. Maternal adipokines, i.e., interleukin 6 (IL-6), tumor necrosis factor alpha (TNF- $\alpha$ ), leptin and adiponectin link maternal nutritional status and adipose tissue metabolism to placental function. Adipokines and metabolic hormones have direct impact on placental function by modulating placental nutrient transport. Nutrient delivery to the fetus is regulated by a complex interaction including insulin signaling, cytokine profile and insulin responsiveness, which is modulated by adiponectin and IL-1 $\beta$. In addition, obese pregnant women are at risk for hypertension and preeclampsia with reduced placental vascularity and blood flow, which would restrict placental nutrient delivery to the developing fetus. These sometimes opposing signals regulating placental function may contribute to the diversity of short and long-term outcomes observed in pregnant obese women. This review focuses on the changes in adipokines and obesity-related metabolic hormones, how these factors influence placental function and fetal development to contribute to long-term metabolic and behavioral consequences of children born to obese mothers.

Reproduction (2017) 153 R97-R108
\end{abstract}

\section{Introduction}

Obesity currently affects approximately one-third of reproductive age women leading to a high prevalence of obesity in pregnancy (Flegal et al. 2012). Maternal obesity is associated with an increased risk for obstetrical complications such as gestational diabetes mellitus (GDM), gestational hypertension, preeclampsia, preterm delivery and caesarian section (Sohlberg et al. 2012, Lim \& Mahmood 2015, Lutsiv et al. 2015, Mission et al. 2015, Maclnnis et al. 2016) and increased neonatal morbidity and mortality (Lim \& Mahmood 2015, Marchi et al. 2015, Santangeli et al. 2015). In addition to adverse short-term outcomes, both the obese mother and her child are prone to develop cardiovascular, metabolic and neurological disorders later in life (LaCoursiere et al. 2010, Nguyen et al. 2015, Rivera et al. 2015, Stang \& Huffman 2016).

Maternal obesity influences both placenta and the fetus, often resulting in fetal overgrowth and a greater frequency of large for gestational age (LGA) infants (Stang \& Huffman 2016). Placental nutrient transport capacity has been shown to be increased in animal models of maternal obesity and is strongly associated to birth weight in humans, providing mechanistic insight into the accelerated fetal growth associated with maternal obesity (Jones et al. 2009b, Jansson et al. 2013, Acosta et al. 2015, Rosario et al. 2015, Lager et al. 2016). Interestingly, non-branching placental angiogenesis has been reported in maternal obesity (Dubova et al. 2011). This finding may contribute to reduced placental blood flow found in hypertensive obstetric complications such as preeclampsia (Moran et al. 2015) in pregnancies complicated by obesity. As in lean women, hypertension in pregnancy and poor placental vascularity in maternal obesity are associated with fetal growth restriction rather than LGA.

Children born to obese mothers are more likely to develop childhood obesity and metabolic disease (Boney et al. 2005, Hermann et al. 2010, Santangeli et al. 2015), and this is especially true for those who were born LGA or macrosomic ( $>4 \mathrm{~kg}$ ). Infants of obese mothers are prone to develop hyperinsulinemia and hypoglycemia in the neonatal period (Avcl et al. 2015), which may, in part, be due to the development of GDM in some obese mothers (Desoye \& van Poppel 2015). Animal studies have shown that maternal obesogenic diets 
induce insulin resistance in the dam and increase fetal blood glucose levels leading to accelerated pancreatic $\beta$-cell maturation and impaired glucose tolerance in the offspring (Ford et al. 2009). Long-term studies have shown that children born to obese mothers also have increased susceptibility to develop neuropsychiatric and mood disorders (Bolton \& Bilbo 2014, Rivera et al. 2015) and increased risk of cognitive impairments (Hinkle et al. 2012, 2013, Tanda et al. 2013, Adane et al. 2016). Thus, in utero exposure to maternal obesity programs the fetus for both metabolic and neuropsychiatric disease later in life, and recent studies indicate that placental function plays a critical role in linking intrauterine environment to long-term health risk (Heerwagen et al. 2010, Smith \& Ryckman 2015, Dimasuay et al. 2016).

Given the high prevalence of obesity in pregnancy as a result of the current obesity epidemic worldwide, the adverse effects of maternal obesity for mother and child represent a major public health concern. However, although associations between obesity and maternal-fetal health are clear, the mechanisms linking the obese maternal environment to short- and long-term outcomes are complex and remain largely unknown. In this review, we will examine the changes in maternal adipokines and obesity-related metabolic hormones and how these factors influence placental function and fetal development, and may contribute to long-term health consequences of children born to obese mothers.

\section{The impact of adipokines and metabolic hormones on placental function, fetal growth and development}

Reproduction is tightly regulated by maternal energy balance, and adipokines play a significant role in creating a favorable environment for implantation and placental development (Reverchon et al. 2014, Dos Santos et al. 2015). During pregnancy, the placenta secretes cytokines and increases both the local and systemic levels, believed to be important in determining fetal allograft fate (Wedekind \& Belkacemi 2016). The placenta produces an array of cytokines including tumor necrosis factor alpha (TNF- $\alpha$ ), interleukin-6 (IL-6) and interleukin 1-beta (IL-1 $\beta$ ) (Hauguel-de Mouzon \& Guerre-Millo 2006), which likely contribute to the elevation in circulating maternal inflammatory cytokines during pregnancy. Interestingly, cytokines may play distinct, yet significant, roles in placental development and function across gestation.

Maternal obesity has been associated with lowgrade metabolic inflammation due to increased release of adipokines, which are believed to contribute to maternal glucose intolerance and insulin resistance and cardiovascular and neuroendocrine modulation associated with increased maternal BMI (Segovia et al. 2014). Increased cytokine and decreased adiponectin release from adipose tissue has been linked to the metainflammatory state of obesity (Khodabandehloo et al. 2016, Luo \& Liu 2016). Although the concept of lowgrade inflammation with obesity is widely accepted, an increased pro-inflammatory cytokine profile in obese mothers has not been consistently reported and appears to be modulated with advancing gestation (Stewart et al. 2007, Friis et al. 2013, Christian \& Porter 2014). A significant pro-inflammatory activation may not occur in the developing human fetus of obese mothers (Aye et al. $2014 b$, Pantham et al. 2015) or may be present only in severe obesity (body mass index $>35 \mathrm{~kg} / \mathrm{m}^{2}$ ) (Dosch et al. 2016). However, even if direct fetal exposure to maternal cytokines may be limited, cytokines in the maternal circulation have been proposed to modulate placental growth and function, which in turn influences fetal development.

\section{TNF- $\alpha$}

In normal pregnancy, there is an increase in placental secretion of TNF- $\alpha$ and vascular endothelial growth factor (VEGF), which is believed to promote normal placental angiogenesis and growth (Pavlov et al. 2016). It has recently been discovered that TNF- $\alpha$ stimulates the production of a member of the VEGF family, placental growth factor (PIGF), in trophoblasts (Kato et al. 2016). TNF- $\alpha$ is a key regulator of implantation and trophoblast function in the first trimester and has been shown to induce apoptosis in cultured trophoblast cells (Knöfler et al. 2000, Pavlov et al. 2016, Siwetz et al. 2016). Thus, TNF- $\alpha$ appears to be important for trophoblast turnover and differentiation and overall placental development, a concept supported by the increasing maternal serum TNF- $\alpha$ levels across gestation (Christian \& Porter 2014). However, reports of significantly elevated circulating TNF- $\alpha$ in obese compared to lean women are inconsistent (Stewart et al. 2007, Friis et al. 2013, Aye et al. 2014b, Christian \& Porter 2014, Stone et al. 2014). Interestingly, TNF- $\alpha$ promotes apoptosis in villous trophoblasts from IUGR placentas compared to controls (Crocker et al. 2003). Intra-amniotic infusion of IL-1 $\beta$ and TNF- $\alpha$ have been reported to induce pre-term labor in nonhuman primates (Sadowsky et al. 2006). Taken together, elevated TNF- $\alpha$ is critical for implantation, and normal placental development and variations found in TNF- $\alpha$ levels associated with maternal obesity may contribute to the diversity of obstetrical outcomes associated with this pregnancy complication.

\section{IL-6}

A number of studies report increased circulating levels of IL-6 in obese pregnant women as compared to women with normal BMI (Stewart et al. 2007, Christian \& Porter 2014); however, this finding could not be confirmed by 
all investigators (Stone et al. 2007, Aye et al. 2014b). Importantly, Friis and coworkers (Friis et al. 2013) demonstrated that maternal IL-6 was elevated early in pregnant obese mothers, but this difference was lost with advancing gestation. Low-grade inflammatory activation associated with maternal obesity may lead to increased placental nutrient transport capacity and promote fetal growth, because both IL- 6 and TNF- $\alpha$ have been shown to stimulate placental System $A$ amino acid transport (Jones et al. 2009a, Aye et al. 2015). Expression of the System A isoform sodium coupled neutral amino acid transporter 2 (SNAT2) was increased after IL-6 and TNF- $\alpha$ stimulation. IL- 6 upregulated phosphorylation of signal transducer and activator of transcription 3 (STAT3) and using siRNA-mediated silencing of STAT3, it was demonstrated that STAT3 activation constitutes a critical mechanistic link between IL-6 and increased amino acid transport (Jones et al. 2009a). IL-6 also upregulates fatty acid uptake in human trophoblast cells, which would contribute to excessive fat deposition associated with babies born to obese mothers (Lager et al. 2011). TNF- $\alpha$ was found to mediate the upregulation of trophoblast System A through p38MAPK signaling, independent from the STAT3 pathway (Aye et al. 2015), demonstrating that pro-inflammatory cytokines regulate placental function by the activation of multiple signaling pathways.

\section{Adiponectin}

Adiponectin, an adipokine inversely correlated with insulin resistance, plays a crucial role in regulating immune responses, energy metabolism and placental insulin sensitivity (Ruan \& Dong 2016). Lean women have higher adiponectin compared to obese women throughout pregnancy (Jansson et al. 2008), and maternal levels of adiponectin are inversely correlated with fetal growth, implicating a role for adiponectin in fetal development, metabolism and placental function (Aye et al. 2013, 2015, Duval et al. 2016). Adiponectin was shown to cause placental insulin resistance in cultured primary human trophoblast cells (Jones et al. 2010), which is in contrast to the insulin sensitizing effects of adiponectin in other tissues, including skeletal muscle (Liu et al. 2013). In trophoblasts, activation of PPAR $\alpha$ and increased transcription of ceramide synthase results in increased intracellular ceramide, inhibiting IRS-1 phosphorylation thereby reducing placental insulin responsiveness (Aye et al. 2014a). High adiponectin in lean women is therefore believed to limit placental nutrient transfer and fetal growth, in particular when insulin is high postprandially. In contrast, low circulating adiponectin in obese mothers will not effectively limit insulin's effect on placental function leading to increased placental nutrient transfer and fetal growth. The adiponectin/insulin interaction at the level of the placenta in lean and obese mothers is illustrated in Fig. $1 \mathrm{~A}$ and $\mathrm{B}$.
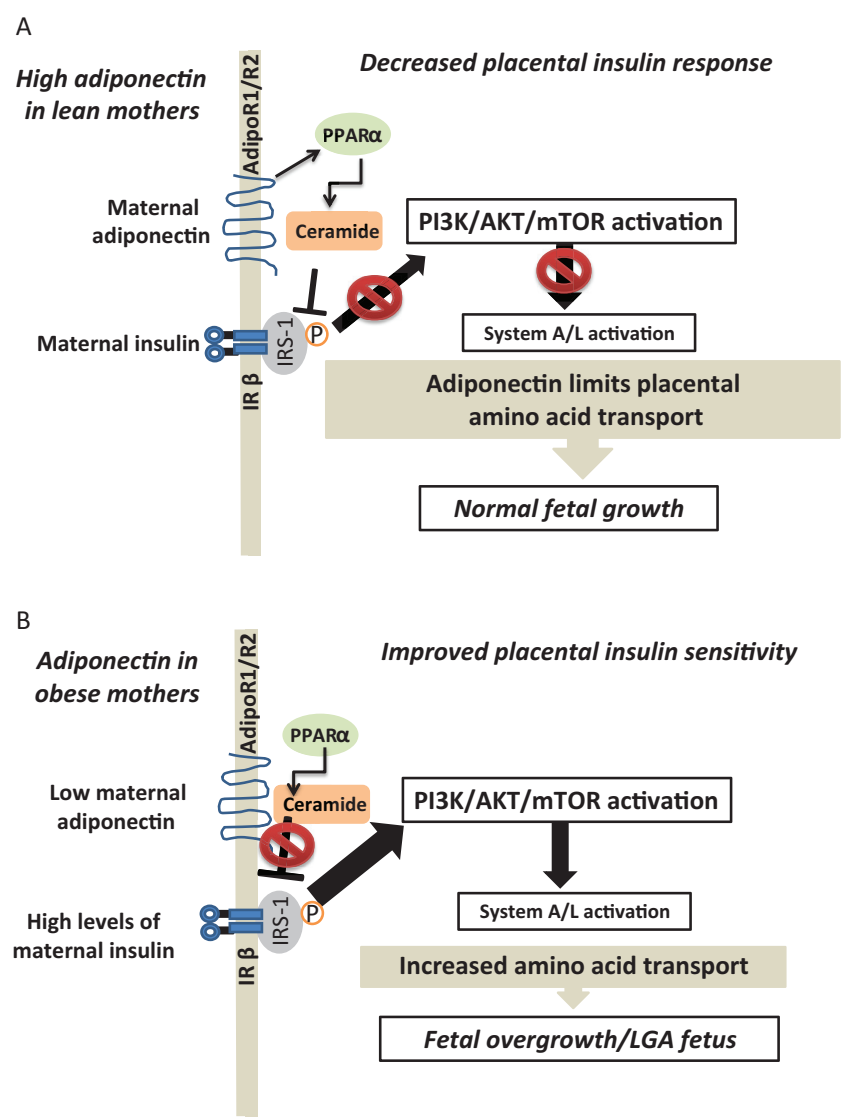

Figure 1 The role of adiponectin in lean and obese women to modulate fetal growth. (A) Adiponectin's influence on placental insulin response in lean mothers. Placental insulin signaling pathway in lean women where high levels of adiponectin leads to PPAR $\alpha$ activation and ceramide synthesis to decrease placental insulin responsiveness through IRS-1 inhibition limiting amino acid transport to modulate fetal growth. (B) Low maternal adiponectin in maternal obesity leads to fetal overgrowth. Low adiponectin in obese mothers allows for enhanced placental insulin sensitivity and activation of placental amino acid transport. This supports fetal overgrowth, which is associated with maternal obesity.

Maternal adiponectin has been shown to be a powerful regulator of placental function and fetal growth in normal and high-fat diet-induced obese pregnant mice (Aye et al. 2015, Rosario et al. 2015). Specifically, infusion of full-length adiponectin to normal pregnant mice results in downregulation of placental nutrient transport and fetal growth restriction (Rosario et al. 2012). Maternal infusion of adiponectin in obese dams normalized maternal insulin sensitivity, placental insulin/mTORC1 signaling, nutrient transport and fetal growth (Aye et al. 2015).

Placental nutrient transporter expression has been shown to be increased in human pregnancies complicated by obesity and is strongly correlated with birth weight. This relationship has been described for most macronutrients including glucose (Acosta et al. 2015), fatty acid (Lager et al. 2016) and amino acid 
transporters (Jansson et al. 2013) in placenta from women of varying pre-gestational BMI. The underlying mechanisms for regulating the expression of these placental transporters are complex and not yet well understood. However, studies in mice suggest that improving maternal adiponectin levels in obese mothers may serve as an effective intervention strategy to prevent fetal overgrowth and the intrauterine transmission of obesity and metabolic disease to the next generation (Aye et al. 2015).

\section{Leptin}

Leptin regulates food intake and energy expenditure, and obese individuals have increased circulating leptin levels (Triantafyllou et al. 2016). Obesity is also associated with leptin resistance, impairing the ability of leptin to suppress appetite (Caro et al. 1996, Schwartz et al. 1996). Elevated maternal leptin modulates trophoblast invasion and nutrient supply, which could influence fetal growth (Tessier et al. 2013, Dos Santos et al. 2015). In the later stages of pregnancy when rapid fetal growth occurs, both insulin and leptin upregulate placental System A amino acid transport, to increase fetal nutrient availability (Jansson et al. 2003, Ericsson et al. 2005, von Versen-Höynck et al. 2009). Increased placental nutrient delivery as a result of altered maternal levels of metabolic hormones, such as leptin, in the maternal circulation has been proposed to contribute to fetal overgrowth in pregnancies complicated by obesity. Animal studies have demonstrated that offspring exposed to a premature neonatal leptin surge have increased number of hypothalamic nerve terminals and altered appetite regulation. In addition, these offspring show increased postnatal weight gain and develop obesity, suggesting an important role for early-life leptin in determining obesity later in life (Yura et al. 2005). Moreover, altered leptin signaling in utero may predispose the fetus for leptin resistance, which could explain the strong association between maternal obesity in pregnancy and obesity in children (Bouret 2012).

\section{Placental Regulation}

Although many factors contribute to human obesity, this review focuses on humans and studies using highfat diet-induced obesity in animal models. High-fat/ high-sugar diet-induced obesity increased placental amino acid and glucose transport to the fetus and was associated with the activation of placental insulin and mechanistic target of rapamycin (mTOR) signaling and fetal overgrowth (Rosario et al. 2015) in pregnant mice. Additionally, mTOR has been mechanistically linked to the regulation of placental nutrient transport in cultured primary human trophoblast cells. Specifically, mTOR signaling functions as a positive regulator of trophoblast
System $\mathrm{A}$ and $\mathrm{L}$ amino acid transporters (Rosario et al. 2013, 2016a,c) and folate transporters (Rosario et al. 2016b). In human pregnancy, placental mTOR is activated in pregnancies complicated by maternal obesity (Jansson et al. 2013) and inhibited in IUGR (Roos et al. 2007, Chen et al. 2015). These data suggest mTOR signaling is a master regulator of placental nutrient transport capacity and a powerful determinant of fetal growth.

Circulating maternal lipids serve as the source of fatty acids transported across the placentas and may also act as signaling molecules that modulate placental amino acid transporter activity through toll-like receptor 4 (TLR4) signaling (Lager et al. 2013). Carbon chain length and saturation are critical as monounsaturated fats, such as oleic acid (18:1, n-9), stimulates System A activity, whereas the anti-inflammatory omega 3 long chain polyunsaturated fatty acid, docosahexaenoic acid (DHA) inhibits the activity of this amino acid transporter (Lager et al. 2014). In normal pregnancy, TLR4 placental expression increases across gestation (Thaete et al. 2013) and TLR4 has been shown to be present in cytotrophoblasts and syncytiotrophoblasts (Mitsunari et al. 2006). Placental TLR4 expression has been reported to be elevated threefold to ninefold in obese mothers and is positively correlated to maternal and placental IL-6 expression (Yang et al. 2016). Similarly, in women with GDM, placental TLR4 expression is correlated with maternal hyperglycemia and insulin resistance (Feng et al. 2016). In liver, expression of TLR4 constitutes an important mechanistic link between high-fat diet/obesity and insulin resistance (Jia et al. 2014). Moreover, studies in pregnant sheep have demonstrated that inflammation is associated with maternal obesity and upregulates free fatty acid content in the cotyledon through TLR4 activation (Zhu et al. $2010 a, b)$. Studies in human placenta likewise suggest that high maternal BMI promotes TLR4 signaling and propagation of inflammatory responses (Yang et al. 2016). These studies suggest that upregulated placental TLR4 expression may mediate placental inflammation and increased placental transfer of nutrients, including amino acids and fatty acids, thereby contributing to fetal overgrowth and/or increased fat deposition in pregnancies complicated by maternal obesity. The interactions of adipokines and insulin to regulate placental function are illustrated in Fig. 2.

\section{Obstetric complications associated with maternal obesity}

As compared to women with normal BMI, obese mothers have a markedly increased risk to develop GDM, as demonstrated by the high prevalence $(33 \%)$ of obese pregnant women diagnosed with this complication (Farren et al. 2015). Infants of GDM mothers are at 


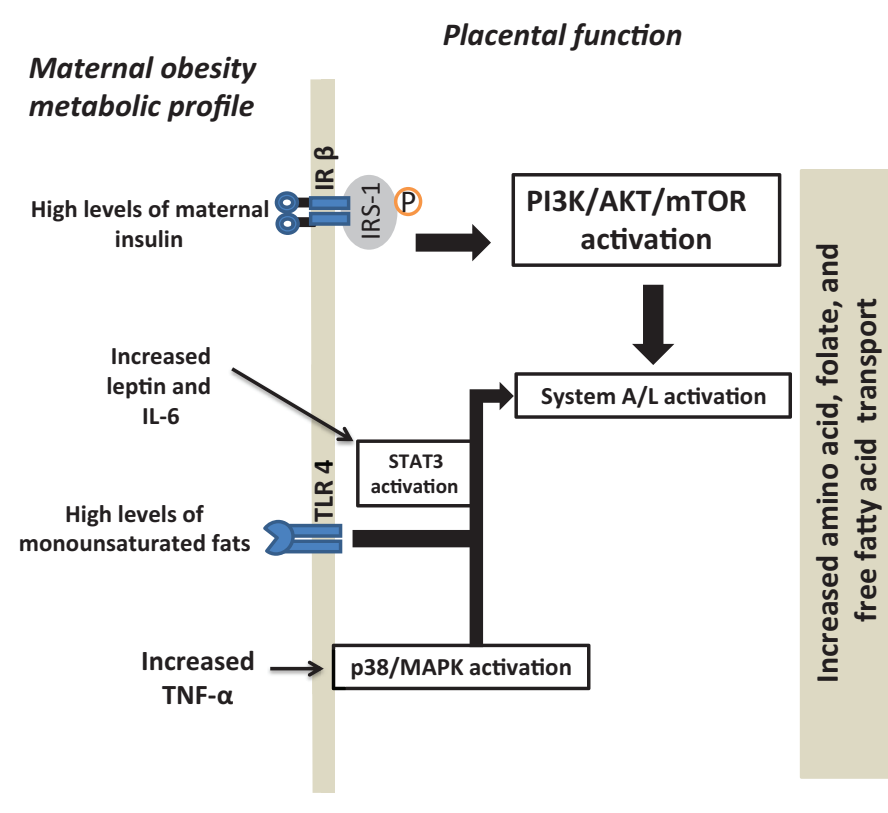

increased risk for LGA (9-18\%) and the risk is particularly high (22-35\%) in obese mothers with GDM (Kim et al. 2014). Obese women are twice as likely to develop preeclampsia and six times more likely to develop gestational hypertension compared to normal weight women (Stang \& Huffman 2016). Hypertensive obstetric complications are generally associated with small-forgestational age neonates (SGA) (Stang \& Huffman 2016). Additionally, there is an increased risk of stillbirth among obese mothers (Yao et al. 2016).

\section{Gestational diabetes}

Obese mothers with GDM are three times more likely to have LGA or macrosomic babies who have increased adiposity and are more likely to be delivered by caesarian section (Harper 2015, Logan et al. 2016). Moreover, GDM diagnosis is associated with increased future risk of obesity, cardiovascular disease and metabolic disease in both mother and child (Stang \& Huffman 2016, Zhao et al. 2016). As discussed previously, maternal meta-inflammation (elevated IL-6, leptin and low adiponectin) may stimulate placental nutrient transport in pregnancies complicated by obesity with GDM contributing to fetal overgrowth (Segovia et al. 2014). Maternal TNF- $\alpha$ levels have been cited as a reliable predictor of insulin sensitivity during pregnancy (Kirwan et al. 2002) and TNF- $\alpha$ stimulates placental nutrient transport (Aye et al. 2015).

Maternal hyperglycemia and increased glucose transport capacity (Acosta et al. 2015) in obesity with GDM are factors believed to promote placental glucose transfer, causing fetal hyperinsulinemia and increased fetal growth (Palatianou et al. 2014, Desoye \& van Poppel 2015). These changes are also likely to represent the underpinnings of hypoglycemia/hyperinsulinemia at
Fetal impact

\author{
Figure 2 Metabolic hormones and adipokine \\ impact on placental function leads to fetal \\ overgrowth. Factors associated with maternal \\ obesity play a significant role in regulating \\ placental transport and impact fetal \\ development. Increased levels of TNF- $\alpha$ \\ observed in pregnancies complicated by \\ obesity stimulate the p38/MAPK pathway and \\ high maternal leptin and/or IL-6 levels \\ stimulate Systems A/L via STAT3 activation. \\ Placental toll-like receptor 4 expression is \\ increased in obese women who often have \\ high non-esterified fatty acids leading to the \\ activation of placental amino acid transport. \\ High maternal insulin also activates mTOR- \\ System $A / L$ to increase amino acid transport, \\ leading to fetal overgrowth.
}

birth in infants of obese mothers (Palatianou et al. 2014, Desoye \& van Poppel 2015). These studies suggest that placental function may be modulated by maternal glycemia, as well as obesity-related inflammation and that these factors are critical for determining the growth trajectory of the developing fetus.

\section{Preeclampsia}

In normal pregnancy, VEGF binds to its receptor, VEGF receptor 1 (Flt1), in the placenta to increase branching, angiogenesis and blood flow (Dubova et al. 2011). However, reduced placental VEGF-Flt1 interaction may explain enhanced non-branching placental angiogenesis in pregnancies complicated by obesity (Dubova et al. 2011). These changes have been proposed to result in a reduction in utero-placental perfusion leading to placental ischemia (Dubova et al. 2011). Placental hypo-perfusion increases the production of IL- 6 and TNF- $\alpha$ (Pierce et al. 2000, Gadonski et al. 2006), perhaps contributing to reports of elevated maternal pro-inflammatory cytokines in some, but not all, obese women. Recent reports have suggested that placental IL-1 $\beta$ expression increases with maternal BMI (Aye et al. 2014b). IL-1 $\beta$ has been associated with preeclampsia and pre-term labor, where this cytokine is hypothesized to contribute to maternal endothelial dysfunction (Amash et al. 2012). IL-1 $\beta$ expression has also been indicated as a mechanism to protect cytotrophoblasts from TNF- $\alpha$ cytotoxicity because IL-1 $\beta$ downregulates the TNF receptor (Knöfler et al. 2000).

PIGF is a member of the VEGF family that binds primarily to the Flt1 receptor and remodels spiral arteries to allow for adequate blood supply to the placenta. Correlative studies have found that increased maternal soluble Flt1 (sFlt1) and decreased PIGF, along with 
reduced PIGF in umbilical cord blood, are associated with reduced birth weight (Bergen et al. 2015). Elevated levels of sFlt1 sequester VEGF and PIGF to reduce their bioavailability for the membrane-bound receptors and therefore disrupts the angiogenic balance required for proper placental vascular remodeling and angiogenesis (Lecarpentier \& Tsatsaris 2016). Preeclampsia is associated with increased maternal serum levels of sFlt1 and pro-inflammatory TNF- $\alpha$ (Spradley et al. 2015), which are linked to maternal hypertensive disorders and fetal growth restriction (Moran et al. 2015, Cetin et al. 2016). Rodent studies indicate that high-fat diets may impair the development of the placental vasculature as evidenced by increased hypoxia in the labyrinth, and fetal death was threefold higher in dams fed high-fat diets (Hayes et al. 2012). The pups that survived were often small for gestational age (Hayes et al. 2012).

Therefore, a critical distinction may be occurring between reduced placental vascularization, which would tend to decrease fetal growth vs stimulation of placental nutrient transfer, thought to accelerate fetal growth. These opposing signals may provide an explanation for the variation in fetal outcomes observed in pregnancies complicated by obesity. IL-1 $\beta$ appears to be consistently associated with hypertensive disorders such as preeclampsia (Kalinderis et al. 2011, Dong \& Yin 2014, Leme Galvão et al. 2016) and may be predictive of future disease in early-to-mid-pregnancy (Siljee et al. 2013, Taylor et al. 2016). Enhanced placental secretion may be the primary source of circulating IL-1 $\beta$ (Amash et al. 2012). In Fig. 3, we have summarized key factors including maternal cytokine, lipid and metabolic hormone profiles that may interact in maternal obesity to cause diverse infant phenotypes at birth.

\section{Long-term outcomes of children born to obese mothers}

Maternal obesity propagates a vicious cycle of metabolic disorders passed down from mother to fetus in utero, with long-lasting impact on child and adult health. Children born to obese mothers have a twofold increased risk for childhood obesity (Zhang et al. 2011). In addition, children born to obese mothers are at increased risk for metabolic, cardiovascular and neurological disorders later in life (LaCoursiere et al. 2010, Nguyen et al. 2015, Rivera et al. 2015, Stang \& Huffman 2016). Pancreatic $\beta$-cell maturation is accelerated in the offspring of obese sheep (Ford et al. 2009). Early exposure to elevated glucose levels is believed to impair pancreatic function, predisposing the offspring for obesity and metabolic disease later in life through early onset of $\beta$-cell dysfunction (Armitage et al. 2004, 2005, Ford et al. 2009).

Long-term longitudinal and associative studies have shown that children born to obese mothers have an increased risk to develop neuropsychiatric and mood disorders and increased risk of cognitive impairments (Hinkle et al. 2012, 2013, Tanda et al. 2013, Bolton \& Bilbo 2014, Rivera et al. 2015, Adane et al. 2016). Animal models of high-fat diet-induced obesity demonstrate that offspring display social impairments, anxiety and depressive phenotypes with cognitive impairment and hyperactivity (Sullivan et al. 2015). Similarly, increased proliferation was observed in the fetal hypothalamus when exposed to high levels of IL-6 in vivo and in vitro (Kim et al. 2016). Elevated maternal TNF- $\alpha$ is associated with obesity (Atègbo et al. 2006, Aye et al. 2014b, Stone et al 2014), pre-term birth and hyperlipidemia (Jelliffe-Pawlowski et al. 2014) and elevated TNF- $\alpha$ from cord blood of pre-term babies has been associated with cognitive deficits at 5 years of age (von Ehrenstein et al. 2012). Interestingly, 35\% of children with autism also suffer from childhood obesity (Granich et al. 2016), further linking the in utero environment with a predisposition for both neurodevelopmental and metabolic disorders. The observed behavioral and cognitive deficits in children of obese mothers may be linked to alterations in the serotonergic system and hypothalamic-pituitaryadrenal (HPA) axis resulting from increased proinflammatory cytokines and high-fat diets (Ford et al. 2009, Sullivan et al. 2015, Kim et al. 2016).

The placenta has recently been identified as a critical source of serotonin for the developing fetus, where it plays a role during intrauterine life by modulating forebrain development (Bonnin et al. 2011). It has been suggested that pregnancy conditions such as maternal stress and inflammation upregulate placental serotonin production to program the developing fetus for neurodevelopmental disorders (St Pierre et al. 2015, Brummelte et al. 2016, Goeden et al. 2016). Increased IL-1 and IL-6 have been identified as potential cytokines linked to changes in placental function and subsequent neurodevelopmental insults that include forebrain damage and behavioral consequences in rodents (Smith et al. 2007, Girard et al. 2010). Importantly, serotonin neurotransmission is impaired in autism and schizophrenia and both disorders are linked to exposure to increased pro-inflammatory cytokines, such as IL-6 in utero (Atladóttir et al. 2010, Brown \& Derkits 2010, Meyer et al. 2011). Recent studies found that maternal IL-6-mediated inflammatory responses influenced fetal neurodevelopment through upregulated conversion of maternal I-tryptophan to serotonin, leading to excess serotonin production by the placenta and blunted fetal forebrain axonal outgrowth (Goeden et al. 2016). Given that IL-6 plays a role in both nutrient delivery and serotonin synthesis, increased IL-6 associated with maternal obesity (Stewart et al. 2007, Friis et al. 2013, 


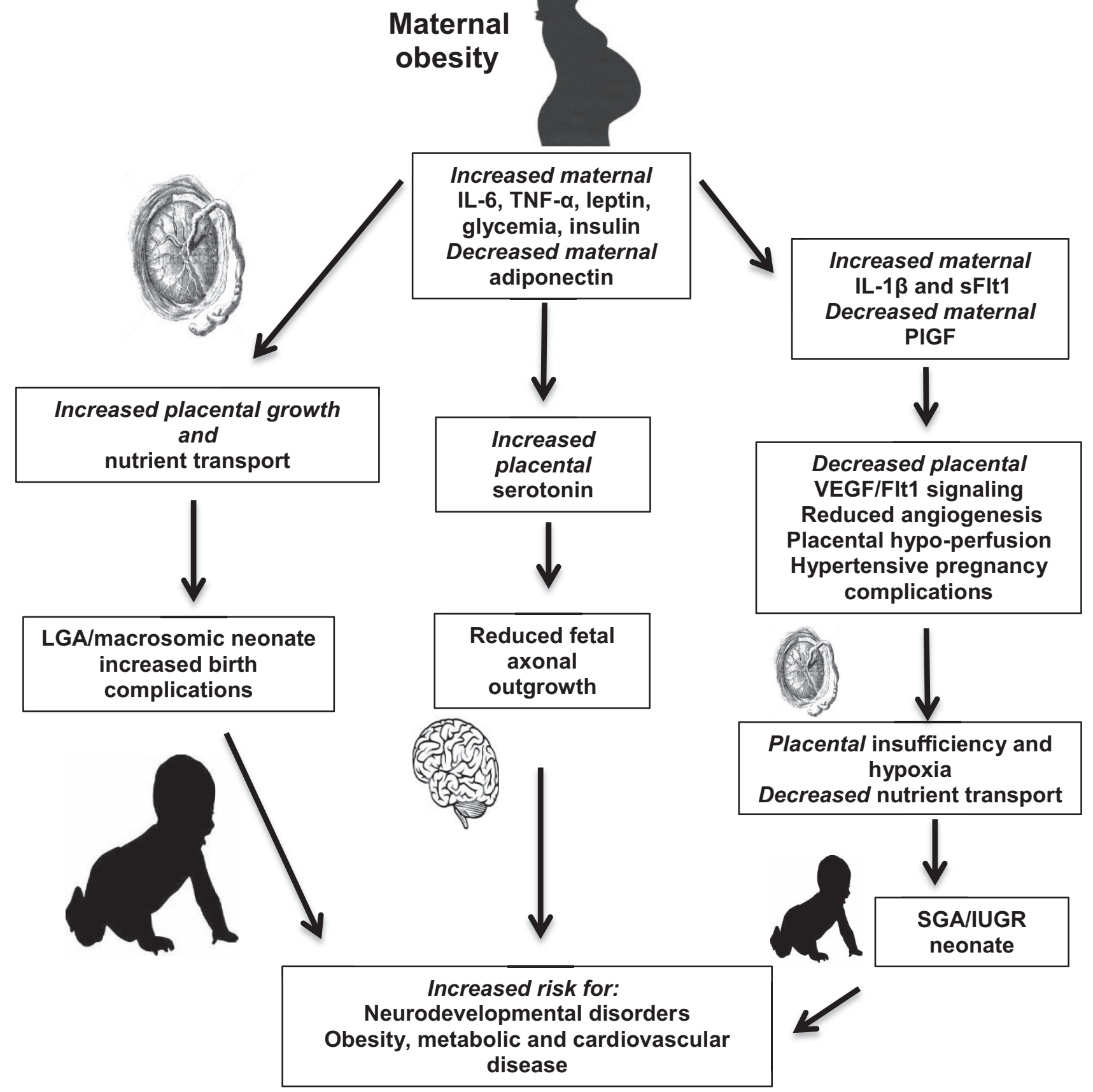

Figure 3 Role of adipokines and metabolic hormones in pregnancies complicated by obesity. Diversity in cytokine profiles in obese women may contribute to variation in fetal growth outcomes. In pregnancies complicated by LGA, multiple metabolic factors, insulin, leptin, IL-6 and TNF- $\alpha$ and low maternal adiponectin have been found to stimulate placental nutrient transport, contributing to fetal overgrowth. In pregnancies complicated by hypertension, IL-1 $\beta$ and sFlt1 are upregulated, whereas PIGF is decreased, leading to reduced placental blood flow, which will limit fetal growth. Fetal brain development and long-term neurodevelopmental programming are linked to inflammation and placental serotonin production. Interestingly, both poor and accelerated fetal growth are associated with similar long-term metabolic disorders in the children.

Christian \& Porter 2014) could significantly alter fetal serotonin balance and program life-long disease and neurocognitive disorders (Bolton \& Bilbo 2014).

Similarly, leptin is a neurotropic factor and appears to be critical for hypothalamic development
(Bouret 2012) and long-term behavioral programming (Farr et al. 2015) in the offspring of obese mothers. Impaired metabolic regulation and leptin resistance in offspring of diabetic animals adversely influences the developing hypothalamus (Steculorum \& Boret 2011, 
López-Gallardo et al. 2015). Leptin deficiency with the loss of placental-derived leptin in growth restricted and pre-term delivered offspring contributes to reduced frontal cortex volume and behavioral deficits in rats (Dexter et al. 2014). Leptin is believed to impact fetal organ growth, including the brain, appetite regulation and cognition during early development (Briffa et al. 2015). Some authors have suggested that leptin replacement in early life may improve long-term metabolic and behavioral outcomes (Chen et al. 2011, Meyer et al. 2014).

\section{Conclusion}

In summary, although numerous cytokines (IL-6, TNF- $\alpha$ and leptin) as well as maternal insulin stimulate placental nutrient transporter activity, other adipokines (IL-1 $\beta$ and adiponectin) inhibit insulin-stimulated nutrient transport. Therefore, multiple maternal adipokines are critical signaling molecules that link maternal nutrient status and adipose tissue metabolism to placental nutrient transport and in turn, impact fetal organ development and alter growth patterns in utero. A clear interaction between cytokine and insulin signaling has been demonstrated in trophoblast cells, but other factors such as maternal dietary fat intake likely influence placental function and are more difficult to quantify in pregnant women. Trophoblast mTOR signaling acts as a nutrientmetabolic sensor by responding to a wide diversity of upstream effectors to regulate expression and membrane trafficking of nutrient transporter proteins; however, other cellular signaling networks within the trophoblast are also involved such as PPARs, STAT3, NFk $\beta$ and $\mathrm{p} 38$ MAPK (Jones et al. 2009a, Aye et al. 2014a, 2015). Therefore, complexity in the regulation of trophoblast function overlays the diversity of maternal signals. Placental vascular development is likely independently regulated, but with similar inflammatory activators, leading to altered angiogenesis in some, but not all, obese women. Specific maternal cytokine profiles associated with particular clinical outcomes are yet to be established. Although important, these studies are difficult and are confounded by the multiple interactions between dietary diversity, maternal adipokines and insulin signaling at the level of the placenta, all of which contribute to the regulation of nutrient transport function, angiogenesis and likely fetal development.

Importantly, increased placental nutrient transport capacity and placental vascular development appear to have opposing regulatory roles in obese mothers. Nutrient transporter activation in obese and GDM mothers plays a significant role in fetal overgrowth. Reduced vascular branching in placentas of obese mothers with hypertensive disorders such as preeclampsia may be an underlying mechanism restricting fetal growth in those pregnancies. Given that obese mothers have significant diversity in fetal growth outcomes, it is important to design effective studies throughout pregnancy to define unique combinations of factors including adipokines, insulin and angiogenic factors that lead to distinct phenotypes among neonates born to obese mothers. For each obese woman, a unique cytokine profile, insulin sensitivity and diet may contribute to determining the growth trajectory and long-term health of her child.

\section{Declaration of interest}

The authors declare that there is no conflict of interest that could be perceived as prejudicing the impartiality of this review.

\section{Funding}

This work was funded in part under grants from $\mathrm{NIH}$ R01DK089989 to T L P (PI) and R01HD065007 to T L P (multi-PI) and T32MH015442, institutional postdoctoral research training program to $\mathrm{KRH}$.

\section{References}

Acosta O, Ramirez VI, Lager S, Gaccioli F, Dudley DJ, Powell TL \& Jansson T 2015 Increased glucose and placental GLUT-1 in large infants of obese nondiabetic mothers. American Journal of Obstetrics and Gynecology 212 227.e1-227.e7. (doi:10.1016/j.ajog.2014.08.009)

Adane AA, Mishra GD \& Tooth LR 2016 Maternal pre-pregnancy obesity and childhood physical and cognitive development of children: a systematic review. International Journal of Obesity 40 1608-1618. (doi:10.1038/ijo.2016.140)

Amash A, Holcberg G, Sapir O \& Huleihel M 2012 Placental secretion of interleukin-1 and interleukin-1 receptor antagonist in preeclampsia: effect of magnesium sulfate. Journal of Interferon and Cytokine Research 32 432-441. (doi:10.1089/jir.2012.0013)

Armitage JA, Khan IY, Taylor PD, Nathanielsz PW \& Poston L 2004 Developmental programming of the metabolic syndrome by maternal nutritional imbalance: how strong is the evidence from experimental models in mammals? Journal of Physiology 561 355-377. (doi:10.1113/ jphysiol.2004.072009)

Armitage JA, Taylor PD \& Poston L 2005 Experimental models of developmental programming: consequences of exposure to an energy rich diet during development. Journal of Physiology 565 3-8. (doi:10.1113/jphysiol.2004.079756)

Atègbo JM, Grissa O, Yessoufou A, Hichami A, Dramane KL, Moutairou K, Miled A, Grissa A, Jerbi M, Tabka Z et al. 2006 Modulation of adipokines and cytokines in gestational diabetes and macrosomia. Journal of Clinical Endocrinology and Metabolism 91 4137-4143. doi:10.1210/ jc.2006-0980

Atladóttir HO, Thorsen P, Østergaard L, Schendel DE, Lemcke S, Abdallah M \& Parner ET 2010 Maternal infection requiring hospitalization during pregnancy and autism spectrum disorders. Journal of Autism and Developmental Disorders 40 1423-1430. (doi:10.1007/s10803-0101006-y)

Avcı ME, Şanlıkan F, Çelik M, Avcı A, Kocaer M \& Göçmen A 2015 Effects of maternal obesity on antenatal, perinatal and neonatal outcomes. Journal of Maternal-Fetal and Neonatal Medicine 28 2080-2083. (doi:1 0.3109/14767058.2014.978279)

Aye IL, Jansson T \& Powell TL 2013 Interleukin-1 $\beta$ inhibits insulin signaling and prevents insulin-stimulated system A amino acid transport in primary human trophoblasts. Molecular and Cellular Endocrinology 381 46-55. (doi:10.1016/j.mce.2013.07.013)

Aye IL, Gao X, Weintraub ST, Jansson T \& Powell TL 2014a Adiponectin inhibits insulin function in primary trophoblasts by PPAR $\alpha$-mediated ceramide synthesis. Molecular Endocrinology 28 512-524. (doi:10.1210/ me.2013-1401) 
Aye IL, Lager S, Ramirez VI, Gaccioli F, Dudley DJ, Jansson T \& Powell TL $2014 b$ Increasing maternal body mass index is associated with systemic inflammation in the mother and the activation of distinct placental inflammatory pathways. Biology of Reproduction 90 129. (doi:10.1095/ biolreprod.113.116186)

Aye IL, Jansson T \& Powell TL 2015 TNF- $\alpha$ stimulates System A amino acid transport in primary human trophoblast cells mediated by p38 MAPK signaling. Physiological Reports 3, pii: e12594. (doi:10.14814/phy2.12594)

Bergen NE, Bouwland-Both MI, Steegers-Theunissen RP, Hofman A, Russcher H, Lindemans J, Jaddoe VW \& Steegers EA 2015 Early pregnancy maternal and fetal angiogenic factors and fetal and childhood growth: the Generation R Study. Human Reproduction 30 1302-1313. (doi:10.1093/humrep/dev070)

Bolton JL \& Bilbo SD 2014 Developmental programming of brain and behavior by perinatal diet: focus on inflammatory mechanisms. Dialogues in Clinical Neuroscience 16 307-320.

Boney CM, Verma A, Tucker R \& Vohr BR 2005 Metabolic syndrome in childhood: association with birth weight, maternal obesity, and gestational diabetes mellitus. Pediatrics 115 e290-e296. (doi:10.1542/ peds.2004-1808)

Bonnin A, Goeden N, Chen K, Wilson ML, King J, Shih JC, Blakely RD, Deneris ES \& Levitt P 2011 A transient placental source of serotonin for the fetal forebrain. Nature 472 347-350. (doi:10.1038/ nature09972)

Bouret SG 2012 Nutritional programming of hypothalamic development: critical periods and windows of opportunity. International Journal of Obesity Supplements 2 (Supplement 2) S19-S24. (doi:10.1038/ ijosup.2012.17

Briffa JF, McAinch AJ, Romano T, Wlodek ME \& Hryciw DH 2015 Leptin in pregnancy and development: a contributor to adulthood disease? American Journal of Physiology: Endocrinology and Metabolism 308 E335-E350. (doi:10.1152/ajpendo.00312.2014)

Brown AS \& Derkits EJ 2010 Prenatal infection and schizophrenia: a review of epidemiologic and translational studies. American Journal of Psychiatry 167 261-280. (doi:10.1176/appi.ajp.2009.09030361)

Brummelte S, Mc Glanaghy E, Bonnin A \& Oberlander TF 2016 Developmental changes in serotonin signaling: implications for early brain function, behavior and adaptation. Neuroscience. In Press. (doi:10.1016/j.neuroscience.2016.02.037)

Caro JF, Kolaczynski JW, Nyce MR, Ohannesian JP, Opentanova I, Goldman WH, Lynn RB, Zhang PL, Sinha MK \& Considine RV 1996 Decreased cerebrospinal-fluid/serum leptin ratio in obesity: a possible mechanism for leptin resistance. Lancet 348 159-161. (doi:10.1016/ S0140-6736(96)03173-X)

Cetin I, Mazzocco MI, Giardini V, Cardellicchio M, Calabrese S, Algeri P, Martinelli A, Todyrenchuk L \& Vergani P 2016 PIGF in a clinical setting of pregnancies at risk of preeclampsia and/or intrauterine growth restriction. Journal of Maternal-Fetal and Neonatal Medicine 19 1-6.

Chen Z, Zhao Y, Yang Y \& Li Z 2011 Leptin withdrawal after birth: a neglected factor account for cognitive deficit in offspring of GDM mother. Medical Hypotheses 77 125-127. (doi:10.1016/j.mehy.2011.03.043)

Chen YY, Rosario FJ, Shehab MA, Powell TL, Gupta MB \& Jansson T 2015 Increased ubiquitination and reduced plasma membrane trafficking of placental amino acid transporter SNAT-2 in human IUGR. Clinical Science 129 1131-1141. (doi:10.1042/CS20150511)

Christian LM \& Porter K 2014 Longitudinal changes in serum proinflammatory markers across pregnancy and postpartum: effects of maternal body mass index. Cytokine 70 134-140. (doi:10.1016/j. cyto.2014.06.018)

Crocker IP, Cooper S, Ong SC \& Baker PN 2003 Differences in apoptotic susceptibility of cytotrophoblasts and syncytiotrophoblasts in normal pregnancy to those complicated with preeclampsia and intrauterine growth restriction. American Journal of Pathology 162 637-643. (doi:10.1016/S0002-9440(10)63857-6)

Desoye G \& van Poppel M 2015 The feto-placental dialogue and diabesity. Best Practice and Research Clinical Obstetrics and Gynaecology 29 15-23. (doi:10.1016/j.bpobgyn.2014.05.012)

Dexter BC, Rahmouni K, Cushman T, Hermann GM, Ni C, Nopoulos PC, Thedens DL \& Roghair RD 2014 Neonatal leptin deficiency reduces frontal cortex volumes and programs adult hyperactivity in mice. Behavioural Brain Research 263 115-121. (doi:10.1016/j.bbr.2014.01.021)
Dimasuay KG, Boeuf P, Powell TL \& Jansson T 2016 Placental responses to changes in the maternal environment determine fetal growth. Frontiers in Physiology 7 12. (doi:10.3389/fphys.2016.00012)

Dong W \& Yin L 2014 Expression of lipoxin A4, TNF $\alpha$ and IL-1 $\beta$ in maternal peripheral blood, umbilical cord blood and placenta, and their significance in pre-eclampsia. Hypertension in Pregnancy 33 449-456. (doi:10.3109/10641955.2014.931419)

Dos Santos E, Duval F, Vialard F \& Dieudonné MN 2015 The roles of leptin and adiponectin at the fetal-maternal interface in humans. Hormone Molecular Biology and Clinical Investigation 24 47-63. (doi:10.1515/ hmbci-2015-0031)

Dosch NC, Guslits EF, Weber MB, Murray SE, Ha B, Coe CL, Auger AP \& Kling PJ 2016 Maternal obesity affects inflammatory and iron indices in umbilical cord blood. Journal of Pediatrics 172 20-28. (doi:10.1016/j. jpeds.2016.02.023)

Dubova EA, Pavlov KA, Borovkova EI, Bayramova MA, Makarov IO \& Shchegolev Al 2011 Vascular endothelial growth factor and its receptors in the placenta of pregnant women with obesity. Bulletin of Experimental Biology and Medicine 151 253-258. (doi:10.1007/s10517-011-1302-3)

Duval F, Santos ED, Poidatz D, Sérazin V, Gronier H, Vialard F \& Dieudonné MN 2016 Adiponectin inhibits nutrient transporters and promotes apoptosis in human villous cytotrophoblasts: involvement in the control of fetal growth. Biology of Reproduction 94111. (doi:10.1095/biolreprod.115.134544)

Ericsson A, Hamark B, Jansson N, Johansson BR, Powell TL \& Jansson T 2005 Hormonal regulation of glucose and system A amino acid transport in first trimester placental villous fragments. American Journal of Physiology: Regulatory Integrative and Comparative Physiology $\mathbf{2 8 8}$ R656-R662. doi:10.1152/ajpregu.00407.2004

Farr OM, Tsoukas MA \& Mantzoros CS 2015 Leptin and the brain: influences on brain development, cognitive functioning and psychiatric disorders. Metabolism 64 114-130. (doi:10.1016/j.metabol.2014.07.004)

Farren M, Daly N, O'Higgins AC, McKeating A, Maguire PJ \& Turner MJ 2015 The interplay between maternal obesity and gestational diabetes mellitus. Journal of Perinatal Medicine 43 311-317. (doi:10.1515/jpm2014-0272)

Feng H, Su R, Song Y, Wang C, Lin L, Ma J \& Yang H 2016 Positive correlation between enhanced expression of TLR4/MyD88/NF-kB with insulin resistance in placentae of gestational diabetes mellitus. PLoS ONE 11 e0157185. (doi:10.1371/journal.pone.0157185)

Flegal KM, Carroll MD, Kit BK \& Ogden CL 2012 Prevalence of obesity and trends in the distribution of body mass index among US adults, 1999-2010. JAMA 307 491-497. (doi:10.1001/jama.2012.39)

Ford SP, Zhang L, Zhu M, Miller MM, Smith DT, Hess BW, Moss GE, Nathanielsz PW \& Nijland MJ 2009 Maternal obesity accelerates fetal pancreatic beta-cell but not alpha-cell development in sheep: prenatal consequences. American Journal of Physiology: Regulatory Integrative and Comparative Physiology 297 R835-R843. (doi:10.1152/ ajpregu.00072.2009)

Friis CM, Paasche Roland MC, Godang K, Ueland T, Tanbo T, Bollerslev J \& Henriksen T 2013 Adiposity-related inflammation: effects of pregnancy. Obesity 21 E124-E130. (doi:10.1002/oby.20120)

Gadonski G, LaMarca BB, Sullivan E, Bennett W, Chandler D \& Granger JP 2006 Hypertension produced by reductions in uterine perfusion in the pregnant rat: role of interleukin 6. Hypertension 48 711-716. (doi:10.1161/01.HYP.0000238442.33463.94)

Girard S, Tremblay L, Lepage M \& Sébire G 2010 IL-1 receptor antagonist protects against placental and neurodevelopmental defects induced by maternal inflammation. Journal of Immunology 184 3997-4005. (doi:10.4049/jimmunol.0903349)

Goeden N, Velasquez J, Arnold KA, Chan Y, Lund BT, Anderson GM \& Bonnin A 2016 Maternal inflammation disrupts fetal neurodevelopment via increased placental output of serotonin to the fetal brain. Journal of Neuroscience 36 6041-6049. (doi:10.1523/JNEUROSCI.2534-15.2016)

Granich J, Lin A, Hunt A, Wray J, Dass A \& Whitehouse AJ 2016 Obesity and associated factors in youth with an autism spectrum disorder. Autism 20 916-929. pii: 1362361315616345. (doi:10.1177/1362361315616345)

Harper LM, Tita A \& Biggio JR 2015 The institute of medicine guidelines for gestational weight gain after a diagnosis of gestational diabetes and pregnancy outcomes. Am / Perinatol 32 239-246. (doi:10.1055/s0034-1383846) 
Hauguel-de Mouzon S \& Guerre-Millo M 2006 The placenta cytokine network and inflammatory signals. Placenta 27 794-798. (doi:10.1016/j. placenta.2005.08.009)

Hayes EK, Lechowicz A, Petrik JJ, Storozhuk Y, Paez-Parent S, Dai Q, Samjoo IA, Mansell M, Gruslin A, Holloway AC et al. 2012 Adverse fetal and neonatal outcomes associated with a life-long high fat diet: role of altered development of the placental vasculature. PLOS One 7 e33370. (doi:10.1371/journal.pone.0033370)

Heerwagen MJ, Miller MR, Barbour LA \& Friedman JE 2010 Maternal obesity and fetal metabolic programming: a fertile epigenetic soil. American Journal of Physiology: Regulatory Integrative and Comparative Physiology 299 R711-R722. (doi:10.1152/ajpregu.00310.2010)

Hermann GM, Dallas LM, Haskell SE \& Roghair RD 2010 Neonatal macrosomia is an independent risk factor for adult metabolic syndrome. Neonatology 98 238-244. (doi:10.1159/000285629)

Hinkle SN, Schieve LA, Stein AD, Swan DW, Ramakrishnan U \& Sharma AJ 2012 Associations between maternal prepregnancy bodymass index and child neurodevelopment at 2 years of age. International Journal of Obesity 36 1312-1319. (doi:10.1038/ijo.2012.143)

Hinkle SN, Sharma AJ, Kim SY \& Schieve LA 2013 Maternal prepregnancy weight status and associations with children's development and disabilities at kindergarten. International Journal of Obesity 37 1344-1351. (doi:10.1038/ijo.2013.128)

Jansson N, Greenwood SL, Johansson BR, Powell TL \& Jansson T 2003 Leptin stimulates the activity of the system A amino acid transporter in human placental villous fragments. Journal of Clinical Endocrinology and Metabolism 88 1205-1211. (doi:10.1210/jc.2002-021332)

Jansson N, Nilsfelt A, Gellerstedt M, Wennergren M, Rossander-Hulthén L, Powell TL \& Jansson T 2008 Maternal hormones linking maternal body mass index and dietary intake to birth weight. American Journal of Clinical Nutrition 87 1743-1749.

Jansson N, Rosario FJ, Gaccioli F, Lager S, Jones HN, Roos S, Jansson T \& Powell TL 2013 Activation of placental mTOR signaling and amino acid transporters in obese women giving birth to large babies. Journal of Clinical Endocrinology and Metabolism 98 105-113. (doi:10.1210/ jc.2012-2667)

Jelliffe-Pawlowski LL, Ryckman KK, Bedell B, O'Brodovich HM, Gould JB, Lyell DJ, Borowski KS, Shaw GM, Murray JC \& Stevenson DK 2014 Combined elevated midpregnancy tumor necrosis factor alpha and hyperlipidemia in pregnancies resulting in early preterm birth. American Journal of Obstetrics and Gynecology 211 141.e1-141.e9. (doi:10.1016/j.ajog.2014.02.019)

Jia L, Vianna CR, Fukuda M, Berglund ED, Liu C, Tao C, Sun K, Liu T, Harper MJ, Lee CE et al. 2014 Hepatocyte Toll-like receptor 4 regulates obesity-induced inflammation and insulin resistance. Nature Communications 5 3878. (doi:10.1038/ncomms4878)

Jones HN, Jansson T \& Powell TL 2009a IL-6 stimulates system A amino acid transporter activity in trophoblast cells through STAT3 and increased expression of SNAT2. American Journal of Physiology: Cell Physiology 297 C1228-C1235. (doi:10.1152/ajpcell.00195.2009)

Jones HN, Woollett LA, Barbour N, Prasad PD, Powell TL \& Jansson T $2009 b$ High-fat diet before and during pregnancy causes marked upregulation of placental nutrient transport and fetal overgrowth in C57/ BL6 mice. FASEB Journal 23 271-278. (doi:10.1096/fj.08-116889)

Jones HN, Jansson T \& Powell TL 2010 Full-length adiponectin attenuates insulin signaling and inhibits insulin-stimulated amino Acid transport in human primary trophoblast cells. Diabetes 59 1161-1170. (doi:10.2337/ db09-0824)

Kalinderis M, Papanikolaou A, Kalinderi K, Ioannidou E, Giannoulis C, Karagiannis V \& Tarlatzis BC 2011 Elevated serum levels of interleukin-6, interleukin-1 $\beta$ and human chorionic gonadotropin in preeclampsia. American Journal of Reproductive Immunology 66 468-475. (doi:10.1111/j.1600-0897.2011.01019.x)

Kato E, Yamamoto T \& Chishima F 2016 Effects of cytokines and TLR ligands on the production of PIGF and sVEGFR1 in primary trophoblasts. Gynecologic and Obstetric Investigation (in press). (doi:10.1159/000446279)

Khodabandehloo H, Gorgani-Firuzjaee S, Panahi G \& Meshkani R 2016 Molecular and cellular mechanisms linking inflammation to insulin resistance and $\beta$-cell dysfunction. Translational Research 167 228-256. (doi:10.1016/j.trsl.2015.08.011)
Kim SY, Sharma AJ, Sappenfield W, Wilson HG \& Salihu HM 2014 Association of maternal body mass index, excessive weight gain, and gestational diabetes mellitus with large-for-gestational-age births. Obstetrics and Gynecology 123 737-744. (doi:10.1097/ AOG.0000000000000177)

Kim DW, Glendining KA, Grattan DR \& Jasoni CL 2016 Maternal obesity leads to increased proliferation and numbers of astrocytes in the developing fetal and neonatal mouse hypothalamus. International Journal of Developmental Neuroscience 53 18-25. (doi:10.1016/j. ijdevneu.2016.06.005)

Kirwan JP, Hauguel-De Mouzon S, Lepercq J, Challier JC, HustonPresley L, Friedman JE, Kalhan SC \& Catalano PM 2002 TNF-alpha is a predictor of insulin resistance in human pregnancy. Diabetes $\mathbf{5 1}$ 2207-2213. (doi:10.2337/diabetes.51.7.2207)

Knöfler M, Mösl B, Bauer S, Griesinger G \& Husslein P 2000 TNF-alpha/ TNFRI in primary and immortalized first trimester cytotrophoblasts. Placenta 21 525-535. doi:10.1053/plac.1999.0501

LaCoursiere DY, Barrett-Connor E, O'Hara MW, Hutton A \& Varner MW 2010 The association between prepregnancy obesity and screening positive for postpartum depression. BJOG: An International Journal of Obstetrics and Gynaecology 117 1011-1018. (doi:10.1111/j.14710528.2010.02569.x)

Lager S, Jansson N, Olsson AL, Wennergren $M$, Jansson $\mathrm{T}$ \& Powell TL 2011 Effect of IL- 6 and TNF- $\alpha$ on fatty acid uptake in cultured human primary trophoblast cells. Placenta 32 121-127. (doi:10.1016/j. placenta.2010.10.012)

Lager S, Gaccioli F, Ramirez VI, Jones HN, Jansson T \& Powell TL 2013 Oleic acid stimulates system $A$ amino acid transport in primary human trophoblast cells mediated by toll-like receptor 4. Journal of Lipid Research 54 725-733. (doi:10.1194/jIr.M033050)

Lager S, Jansson T \& Powell TL 2014 Differential regulation of placental amino acid transport by saturated and unsaturated fatty acids. American Journal of Physiology: Cell Physiology 307 C738-C744. (doi:10.1152/ ajpcell.00196.2014)

Lager S, Ramirez VI, Gaccioli F, Jang B, Jansson T \& Powell TL 2016 Protein expression of fatty acid transporter 2 is polarized to the trophoblast basal plasma membrane and increased in placentas from overweight/obese women. Placenta 40 60-66. (doi:10.1016/j.placenta.2016.02.010)

Lecarpentier E \& Tsatsaris V 2016 Angiogenic balance (sFlt-1/PIGF) and preeclampsia. Annales d'Endocrinologie 77 97-100. (doi:10.1016/j. ando.2016.04.007)

Leme Galvão LP, Menezes FE, Mendonca C, Barreto I, Alvim-Pereira C, Alvim-Pereira F \& Gurgel R 2016 Analysis of association of clinical aspects and IL1B tag SNPs with severe preeclampsia. Hypertension in Pregnancy 35 112-122. (doi:10.3109/10641955.2015.1116554)

Lim CC \& Mahmood T 2015 Obesity in pregnancy. Best Practice and Research Clinical Obstetrics and Gynaecology 29 309-319. (doi:10.1016/j.bpobgyn.2014.10.008)

Liu Y, Turdi S, Park T, Morris NJ, Deshaies Y, Xu A \& Sweeney G 2013 Adiponectin corrects high-fat diet-induced disturbances in muscle metabolomic profile and whole-bodyglucose homeostasis. Diabetes 62 743-752. (doi:10.2337/db12-0687)

Logan KM, Emsley RJ, Jeffries S, Andrzejewska I, Hyde MJ, Gale C, Chappell K, Mandalia S, Santhakumaran S, Parkinson JR et al. 2016 Development of early adiposity in infants of mothers with gestational diabetes mellitus. Diabetes Care 39 1045-1051. (doi:10.2337/dc16-0030)

López-Gallardo $M$, Antón-Fernández A, Llorente R, Mela V, LlorenteBerzal A, Prada C \& Viveros MP 2015 Neonatal treatment with a pegylated leptin antagonist induces sexually dimorphic effects on neurones and glial cells, and on markers of synaptic plasticity in the developing rat hippocampal formation. Journal of Neuroendocrinology 27 658-669. (doi:10.1111/jne.12294)

Luo Y \& Liu M 2016 Adiponectin: a versatile player of innate immunity. Journal of Molecular Cell Biology 8 120-128. (doi:10.1093/jmcb/ mjw012)

Lutsiv O, Mah J, Beyene J \& McDonald SD 2015 The effects of morbid obesity on maternal and neonatal health outcomes: a systematic review and meta-analyses. Obesity Reviews 16 531-546. (doi:10.1111/obr.12283)

MacInnis N, Woolcott CG, McDonald S \& Kuhle S 2016 Population attributable risk fractions of maternal overweight and obesity for 
adverse perinatal outcomes. Scientific Reports 6 22895. (doi:10.1038/ srep22895)

Marchi J, Berg M, Dencker A, Olander EK \& Begley C 2015 Risks associated with obesity in pregnancy, for the mother and baby: a systematic review of reviews. Obesity Reviews 16 621-638. (doi:10.1111/obr.12288)

Meyer U, Feldon J \& Dammann O 2011 Schizophrenia and autism: both shared and disorder-specific pathogenesis via perinatal inflammation? Pediatric Research 69 26R-33R. (doi:10.1203/ PDR.0b013e318212c196)

Meyer LR, Zhu V, Miller A \& Roghair RD 2014 Growth restriction, leptin, and the programming of adult behavior in mice. Behavioural Brain Research 275 131-135. (doi:10.1016/j.bbr.2014.08.054)

Mission JF, Marshall NE \& Caughey AB 2015 Pregnancy risks associated with obesity. Obstetrics and Gynecology Clinics of North America 42 335-353. (doi:10.1016/j.ogc.2015.01.008)

Mitsunari M, Yoshida S, Shoji T, Tsukihara S, Iwabe T, Harada T \& Terakawa N 2006 Macrophage-activating lipopeptide-2 induces cyclooxygenase- 2 and prostaglandin $E(2)$ via toll-like receptor 2 in human placental trophoblast cells. Journal of Reproductive Immunology 72 46-59. (doi:10.1016/j.jri.2006.02.003)

Moran MC, Mulcahy C, Zombori G, Ryan J, Downey P \& McAuliffe FM 2015 Placental volume, vasculature and calcification in pregnancies complicated by pre-eclampsia and intra-uterine growth restriction. European Journal of Obstetrics and Gynecology and Reproductive Biology 195 12-17. (doi:10.1016/j.ejogrb.2015.07.023)

Nguyen MU, Wallace MJ, Pepe S, Menheniott TR, Moss TJ \& Burgner D 2015 Perinatal inflammation: a common factor in the early origins of cardiovascular disease? Clinical Science 129 769-784. (doi:10.1042/ CS20150045)

Palatianou ME, Simos YV, Andronikou SK \& Kiortsis DN 2014 Longterm metabolic effects of high birth weight: a critical review of the literature. Hormone and Metabolic Research 46 911-920. (doi:10.105 5/s-0034-1395561)

Pantham P, Aye IL \& Powell TL 2015 Inflammation in maternal obesity and gestational diabetes mellitus. Placenta 36 709-715. (doi:10.1016/j. placenta.2015.04.006)

Pavlov OV, Niauri DA, Selutin AV \& Selkov SA 2016 Coordinated expression of TNF $\alpha$ - and VEGF-mediated signaling components by placental macrophages in early and late pregnancy. Placenta 42 28-36. (doi:10.1016/j.placenta.2016.04.008)

Pierce BT, Pierce LM, Wagner RK, Apodaca CC, Hume RF Jr, Nielsen PE \& Calhoun BC 2000 Hypoperfusion causes increased production of interleukin 6 and tumor necrosis factor alpha in the isolated,dually perfused placental cotyledon. American Journal of Obstetrics and Gynecology 183 863-867. (doi:10.1067/mob.2000.108887)

Reverchon M, Ramé C, Bertoldo M \& Dupont J 2014 Adipokines and the female reproductive tract. International Journal of Endocrinology 2014 232454. (doi:10.1155/2014/232454)

Rivera HM, Christiansen KJ \& Sullivan EL 2015 The role of maternal obesity in the risk of neuropsychiatric disorders. Frontiers in Neuroscience $\mathbf{9}$ 194. (doi:10.3389/fnins.2015.00194)

Roos S, Jansson N, Palmberg I, Säljö K, Powell TL \& Jansson T 2007 Mammalian target of rapamycin in the human placenta regulates leucine transport and is down-regulated in restricted fetal growth. Journal of Physiology 582 449-459. (doi:10.1113/jphysiol.2007.129676)

Rosario FJ, Schumacher MA, Jiang J, Kanai Y, Powell TL \& Jansson T 2012 Chronic maternal infusion of full-length adiponectin in pregnant mice down-regulates placental amino acid transporter activity and expression and decreases fetal growth. Journal of Physiology 590 1495-1509. (doi:10.1113/jphysiol.2011.226399)

Rosario FJ, Kanai Y, Powell TL \& Jansson T 2013 Mammalian target of rapamycin signalling modulates amino acid uptake by regulating transporter cell surface abundance in primary human trophoblast cells. Journal of Physiology 591 609-625. (doi:10.1113/jphysiol.2012.238014)

Rosario FJ, Kanai Y, Powell TL \& Jansson T 2015 Increased placental nutrient transport in a novel mouse model of maternal obesity with fetal overgrowth. Obesity 23 1663-1670. (doi:10.1002/oby.21165)

Rosario FJ, Dimasuay KG, Kanai Y, Powell TL \& Jansson T 2016a Regulation of amino acid transporter trafficking by mTORC1 in primary human trophoblast cells is mediated by the ubiquitin ligase Nedd4-2. Clinical Science 130 499-512. (doi:10.1042/CS20150554)
Rosario FJ, Powell TL \& Jansson T 2016b Mechanistic target of rapamycin (mTOR) regulates trophoblast folate uptake by modulating the cell surface expression of FR- $\alpha$ and the RFC. Scientific Reports 631705. (doi:10.1038/srep31705)

Rosario FJ, Powell TL \& Jansson T 2016c Activation of placental insulin and mTOR signaling in a mouse model of maternal obesity associated with fetal overgrowth. American Journal of Physiology: Regulatory Integrative and Comparative Physiology 310 R87-R93. (doi:10.1152/ ajpregu.00356.2015)

Ruan H \& Dong LQ 2016 Adiponectin signaling and function in insulin target tissues. Journal of Molecular Cell Biology 8 101-109. (doi:10.1093/ $\mathrm{jmcb} / \mathrm{mjw}$ 014)

Sadowsky DW, Adams KM, Gravett MG, Witkin SS \& Novy MJ 2006 Preterm labor is induced by intraamniotic infusions of interleukin-1 beta and tumor necrosis factor-alpha but not by interleukin- 6 or interleukin-8 in a nonhuman primate model. American Journal of Obstetrics and Gynecology 195 1578-1589. (doi:10.1016/j.ajog.2006.06.072)

Santangeli L, Sattar N \& Huda SS 2015 Impact of maternal obesity on perinatal and childhood outcomes. Best Practice and Research Clinical Obstetrics and Gynaecology 29 438-448. (doi:10.1016/j. bpobgyn.2014.10.009)

Schwartz MW, Peskind E, Raskind M, Boyko EJ \& Porte D Jr 1996 Cerebrospinal fluid leptin levels: relationship to plasma levels and to adiposity in humans. Nature Medicine 2 589-593. (doi:10.1038/ nm0596-589)

Segovia SA, Vickers MH, Gray C \& Reynolds CM 2014 Maternal obesity, inflammation, and developmental programming. BioMed Research International 2014 418975. (doi: 10.1155/2014/418975)

Siljee JE, Wortelboer EJ, Koster MP, Imholz S, Rodenburg W, Visser GH, de Vries A, Schielen PC \& Pennings JL 2013 Identification of interleukin-1 beta, but no other inflammatory proteins, as an early onset preeclampsia biomarker in first trimester serum by bead-based multiplexed immunoassays. Prenatal Diagnosis 33 1183-1188. (doi:10.1002/ pd.4219)

Siwetz M, Blaschitz A, El-Heliebi A, Hiden U, Desoye G, Huppertz B \& Gauster M 2016 TNF- $\alpha$ alters the inflammatory secretion profile of human first trimester placenta. Laboratory Investigation 96 428-438. (doi:10.1038/labinvest.2015.159)

Smith CJ \& Ryckman KK 2015 Epigenetic and developmental influences on the risk of obesity, diabetes, and metabolic syndrome. Diabetes, Metabolic Syndrome and Obesity 8 295-302. (doi:10.2147/DMSO. S61296)

Smith SE, Li J, Garbett K, Mirnics K \& Patterson PH 2007 Maternal immune activation alters fetal brain development through interleukin-6. Journal of Neuroscience 27 10695-10702. (doi:10.1523/ JNEUROSCI.2178-07.2007)

Sohlberg S, Stephansson O, Cnattingius S \& Wikstrom AK 2012 Maternal body mass index, height, and risks of preeclampsia. American Journal of Hypertension 25 120-125. (doi:10.1038/ajh.2011.175)

Spradley FT, Palei AC \& Granger JP 2015 Increased risk for the development of preeclampsia in obese pregnancies: weighing in on the mechanisms. American Journal of Physiology: Regulatory Integrative and Comparative Physiology 309 R1326-R1343. (doi:10.1152/ajpregu.00178.2015)

St Pierre J, Laurent L, King S \& Vaillancourt C 2016 Effects of prenatal maternal stress on serotonin and fetal development. Placenta $\mathbf{4 8}$ (Supplement 1) S66-S71. (doi:10.1016/j.placenta.2015.11.013)

Stang J \& Huffman LG 2016 Position of the academy of nutrition and dietetics: obesity, reproduction, and pregnancy outcomes. Journal of the Academy of Nutrition and Dietetics 116 677-691. (doi:10.1016/j. jand.2016.01.008)

Steculorum SM \& Bouret SG 2011 Maternal diabetes compromises the organization of hypothalamic feeding circuits and impairs leptin sensitivity in offspring. Endocrinology 152 4171-4179. (doi:10.1210/ en.2011-1279)

Stewart FM, Freeman DJ, Ramsay JE, Greer IA, Caslake M \& Ferrell WR 2007 Longitudinal assessment of maternal endothelial function and markers of inflammation and placental function throughout pregnancy in lean and obese mothers. Journal of Clinical Endocrinology and Metabolism 92 969-975. (doi:10.1210/jc.2006-2083)

Stone RA, Silvis A, Jude D \& Chaffin D 2014 Increasing body mass index exacerbates inflammation in obese gravidas. Obstetrics 
and Gynecology 123 (Supplement 1) 81S. (doi:10.1097/01. AOG.0000447406.31798.d3)

Sullivan EL, Riper KM, Lockard R \& Valleau JC 2015 Maternal high-fat diet programming of the neuroendocrine system and behavior. Hormones and Behavior 76 153-161. (doi:10.1016/j.yhbeh.2015.04.008)

Tanda R, Salsberry PJ, Reagan PB \& Fang MZ 2013 The impact of prepregnancy obesity on children's cognitive test scores. Maternal and Child Health Journal 17 222-229. (doi:10.1007/s10995-012-0964-4)

Taylor BD, Tang G, Ness RB, Olsen J, Hougaard DM, Skogstrand K, Roberts JM \& Haggerty CL 2016 Mid-pregnancy circulating immune biomarkers in women with preeclampsia and normotensive controls. Pregnancy Hypertension 6 72-78. (doi:10.1016/j. preghy.2015.11.002)

Tessier DR, Ferraro ZM \& Gruslin A 2013 Role of leptin in pregnancy: consequences of maternal obesity. Placenta 34 205-211. (doi:10.1016/j. placenta.2012.11.035)

Thaete LG, Qu XW, Jilling T, Crawford SE, Fitchev P, Hirsch E, Khan S \& Neerhof MG 2013 Impact of toll-like receptor 4 deficiency on the response to uterine ischemia/reperfusion in mice. Reproduction $\mathbf{1 4 5}$ 517-526. (doi:10.1530/REP-12-0433)

Triantafyllou GA, Paschou SA \& Mantzoros CS 2016 Leptin and hormones: energy homeostasis. Endocrinology and Metabolism Clinics of North America 45 633-645. (doi:10.1016/j.ecl.2016.04.012)

von Ehrenstein OS, Neta GI, Andrews W, Goldenberg R, Goepfert A \& Zhang J 2012 Child intellectual development in relation to cytokine levels in umbilical cord blood. American Journal of Epidemiology 175 1191-1199. (doi:10.1093/aje/kwr393)

von Versen-Höynck F, Rajakumar A, Parrott MS \& Powers RW 2009 Leptin affects system A amino acid transport activity in the human placenta: evidence for STAT3 dependent mechanisms. Placenta 30 361-367. (doi:10.1016/j.placenta.2009.01.004)

Wedekind L \& Belkacemi L 2016 Altered cytokine network in gestational diabetes mellitus affects maternal insulin and placentalfetal development. Journal of Diabetic Complications 30 1393-1400. (doi:10.1016/j.jdiacomp.2016.05.011)

Yang X, Li M, Haghiac M, Catalano PM, O'Tierney-Ginn P \& Hauguel-de Mouzon S 2016 Causal relationship between obesity-related traits and
TLR4-driven responses at the maternal-fetal interface. Diabetologia $\mathbf{5 9}$ 2459-2466. (doi:10.1007/s00125-016-4073-6)

Yao R, Park BY \& Caughey AB 2016 The effects of maternal obesity on perinatal outcomes among those born small for gestational age. Journal of Maternal-Fetal and Neonatal Medicine In press. (doi:10.1080/14767058.2016.1216098)

Yura S, Itoh H, Sagawa N, Yamamoto H, Masuzaki H, Nakao K, Kawamura M, Takemura M, Kakui K, Ogawa Y et al. 2005 Role of premature leptin surge in obesity resulting from intrauterine undernutrition. Cell Metabolism $\mathbf{1}$ 371-378. (doi:10.1016/j.cmet.2005.05.005)

Zhang S, Rattanatray L, Morrison JL, Nicholas LM, Lie S \& McMillen IC 2011 Maternal obesity and the early origins of childhood obesity: weighing up the benefits and costs of maternalweight loss in the periconceptional period for the offspring. Experimental Diabetes Research 2011585749. (doi: 10.1155/2011/585749)

Zhao P, Liu E, Qiao Y, Katzmarzyk PT, Chaput JP, Fogelholm M, Johnson WD, Kuriyan R, Kurpad A, Lambert EV et al. 2016 Maternal gestational diabetes and childhood obesity at age 9-11: results of a multinational study. Diabetologia 59 2339-2348. (doi:10.1007/s00125016-4062-9)

Zhu MJ, Du M, Nathanielsz PW \& Ford SP 2010a Maternal obesity up-regulates inflammatory signaling pathways and enhances cytokine expression in the mid-gestation sheep placenta. Placenta 31 387-391. (doi:10.1016/j.placenta.2010.02.002)

Zhu MJ, Ma Y, Long NM, Du M \& Ford SP 2010b Maternal obesity markedly increases placental fatty acid transporter expression and fetal blood triglycerides at midgestation in the ewe. American Journal of Physiology: Regulatory Integrative and Comparative Physiology 299 R1224-R1231. (doi:10.1152/ajpregu.00309.2010)

Received 9 September 2016

First decision 13 October 2016

Revised manuscript received 10 November 2016

Accepted 18 November 2016 